\title{
Estimating migration patterns of fish from otolith chemical composition time-series
}

\author{
Albertsen, Christoffer Moesgaard; Hüssy, Karin; Hansen Serre, Simon; Hansen, Jakob Hemmer; \\ Thomsen, Tonny Bernt
}

Published in:

Canadian Journal of Fisheries and Aquatic Sciences

Link to article, DOI:

$10.1139 /$ cjfas-2020-0356

Publication date:

2021

Document Version

Peer reviewed version

Link back to DTU Orbit

Citation (APA):

Albertsen, C. M., Hüssy, K., Hansen Serre, S., Hansen, J. H., \& Thomsen, T. B. (2021). Estimating migration patterns of fish from otolith chemical composition time-series. Canadian Journal of Fisheries and Aquatic Sciences, 78, 1512-1523. https://doi.org/10.1139/cjfas-2020-0356

\section{General rights}

Copyright and moral rights for the publications made accessible in the public portal are retained by the authors and/or other copyright owners and it is a condition of accessing publications that users recognise and abide by the legal requirements associated with these rights.

- Users may download and print one copy of any publication from the public portal for the purpose of private study or research.

- You may not further distribute the material or use it for any profit-making activity or commercial gain

- You may freely distribute the URL identifying the publication in the public portal

If you believe that this document breaches copyright please contact us providing details, and we will remove access to the work immediately and investigate your claim 


\title{
Estimating migration patterns of fish from otolith chemical composition time-series
}

\author{
Christoffer Moesgaard Albertsen ${ }^{1}$, Karin Hüssy ${ }^{1}$, Simon Hansen Serre ${ }^{2}$, \\ Jakob Hemmer-Hansen ${ }^{3}$, and Tonny Bernt Thomsen ${ }^{2}$ \\ ${ }^{1}$ National Institute of Aquatic Resources, Technical University of Denmark, \\ Kemitorvet 201, DK-2800 Kgs. Lyngby, Denmark \\ ${ }^{2}$ Geological Survey of Denmark and Greenland, Øster Voldgade 10, DK-1350 \\ Copenhagen, Denmark \\ ${ }^{3}$ National Institute of Aquatic Resources, Technical University of Denmark, \\ Vejlsøvej 39, DK-8600 Silkeborg, Denmark
}

\begin{abstract}
Understanding migration patterns and habitat use is of great importance for management and conservation of marine living resources. The chemical composition of otoliths is influenced by the surrounding environment; therefore, they are indispensable data archives. To extract migration patterns and historical habitat use of individual fish, we analyse otolith chemical compositions obtained by laser ablation inductively coupled plasma mass spectrometry by a regime-switching state-space model. The state-space model filters the measurement noise from the environmental signal. In turn, the filtered signal is converted to geographical positions through a calibration of strontium to salinity. The method is validated by a simulation study and applied to 404 Atlantic cod otoliths.
\end{abstract}

Key words: Habitat use, microchemistry, movement, otolith, state-space model, strontium 


\section{Introduction}

Understanding life history, habitat use and migration patterns is vital for management and conservation of marine resources. Knowledge of migration patterns are needed to evaluate the potential effects of marine protected areas and fisheries closures. Further, fish migrating between, or stocks mixing in, management areas provide a challenge for accurately assessing stock status. For many stocks, otoliths (ear-stones) are regularly collected for ageing or for stock separation. In these cases, otoliths also provide an indispensable data archive for analysis of life history and space use.

Otoliths are part of the hearing and balance system in fishes. They grow through daily accretion of calcium carbonate, trace elements and protein, forming both daily and seasonal growth rings, much like the year rings in trees. These properties have made otoliths an invaluable tool for fisheries scientists and form the basis for applications ranging from research into processes affecting individual fish to population ecology and stock assessment. Since the discovery that concentrations of trace elements incorporated into the fish's otolith may reflect concentrations in the ambient water (Edmonds et al., 1989; Kalish, 1989), the analysis of otolith chemical compositions has gained interest for studies of stock structure, habitat connectivity and migration patterns (see reviews in Campana et al., 1999; Sturrock et al., 2012).

The most prominent example of an element's applicability for reconstruction of migration patterns is strontium ( $\mathrm{Sr}$ ), which since the mid 1990s has been considered a useful proxy for environmental salinity, thereby providing a reliable tool for tracking (Limburg, 1995; Secor et al., 1995). Sr concentration is fairly constant across marine habitats worldwide (Walther and Limburg, 2012), and therefore intrusion from freshwater dilutes not only salinity but also the Sr concentration (Kraus and Secor, 2004). Even though the relationship between Sr and salinity is considered relatively constant in marine habitats, concentration of Sr in freshwater may vary, and even exceed those in marine waters, thereby influencing that relationship (Kraus and Secor, 2004). Careful evaluation of the underlying relationship between salinity and otolith $\mathrm{Sr}$ concentration is therefore necessary for reliable reconstruction of migration patterns.

To date, most studies have focused on documenting spatial and/or temporal differences in elemental compositions between groups of fish and examining which biological and environmental variables affect variability in incorporation rates (Sturrock et al., 2012, and references therein). Between-group differences are often studied by statistical comparison of elemental compositions within specific time periods in the fish's life. This is achieved by collecting data within pre-defined growth zones, typically the nucleus and the edge representing environmental conditions at hatch and capture (Gibb et al., 2017; Kennedy et al., 2002; Stanley et al., 2015). Alternatively, data can be divided chronologically from nucleus to edge into strata of known duration, predominantly years, in the fish's life (Albuquerque et al., 2012; Altenritter et al., 2018; Hughes et al., 2016; Jessop et al., 2002; Secor and Piccoli, 1996). The division of data is followed by comparisons of mean elemental concentrations between time periods and groups by, for instance, univariate, multivariate statistics and discriminant analyses (e.g., Hughes et al., 2016; Secor and Piccoli, 1996), logistic functions (e.g., Albuquerque et al., 2012), boosted regression trees (e.g., Cappo et al., 2005) or random forests (e.g., Loewen et al., 2015; Mercier et al., 2012). 
Reconstruction of individual fish's migrations makes use of all measurements along the chronological data profile from hatch to death by classifying each data point into a specific habitat. Approaches reported are often based on classifications' threshold values or sequential analysis of data along the profile. The threshold-based classification uses visual determination of threshold values (Elsdon and Gillanders, 2005a; Jessop et al., 2002, 2008), followed by qualitative evaluation of profiles by comparing edge values representing known capture locations with values earlier in life (Hamer et al., 2006). Threshold values may also be estimated from field measured, habitat-specific elemental otolith concentrations (Seeley and Walther, 2018) or from laboratory experiments (Altenritter et al., 2018). Quantitative analyses of chemical measurements along the chronological profiles include algorithms for regime-shift using sequential t-tests (e.g., Seeley et al., 2017), global zoning (e.g., Hedger et al., 2008; Morissette et al., 2016), mixed effects models (e.g., Grammer et al., 2017; Roberts et al., 2019), individual-based simulation models (Sakamoto et al., 2018), and random forests (e.g., Mercier et al., 2012). Further, Fablet et al. (2007) used a hidden Markov model to infer habitat type preference based on Sr:Ca ratios. The model consisted of two layers: a discrete, unobserved Markov model describing the current habitat type, and a model for observed Sr:Ca ratios which were assumed to be independent given the habitat type and covariates.

In this paper, we introduce a method to infer habitat use patterns throughout the fish's life history from otolith chemical compositions. A time series model is proposed to reconstruct life history trace element concentrations, such as $\mathrm{Sr}$, in the otolith from noisy chemical compositions. The model consists of three layers. Similar to Fablet et al. (2007), a discret, unobserved Markov model is used to describe the current habitat preference. However, to account for measurement error in the model, we introduce a model layer describing the true, unobserved element concentration in the otolith given the current habitat preference. Further, this model layer introduces temporal correlation in the element concentrations besides the habitat type to reflect that fish may move between habitats at time scales that are longer than the time between measurements. Finally, the third model layer describes the observed chemical composition given the true, unobserved concentration. Unlike Fablet et al. (2007), we are not only interested in the current habitat type, but also geographical positions. Therefore, geographical positions are inferred based on the Sr concentration at the otolith edge and corresponding salinity at the catch position. A simulation study is conducted to validate the method proposed. Finally, the method is illustrated using otoliths from the four Atlantic cod (Gadus morhua L.) stocks around Denmark: North Sea, Kattegat, Western Baltic, and Eastern Baltic cod. The method is not specific to Sr and can be applied to any trace element, or combination of elements, that can be related to geographical positions in a study region of interest.

\section{Materials and Methods}

Our method for inferring life history habitat use patterns from otolith chemical composition consisted of four steps. First, the extracted otoliths were prepared and the chemical composition along a transect from the nucleus to the edge was obtained by laser ablation inductively coupled plasma mass spectrometry (LA-ICP-MS). Afterwards, the noisy mass spectrometry data was analysed by a statistical time series model to obtain an estimated trajectory of, for 
instance, Sr concentration. Then, Sr concentrations at the otolith edges and salinity at the capture positions were used to estimate the most likely salinity at a given Sr concentration through a calibration curve. Finally, the estimated salinity from the otolith nucleus to the edge could be compared to ocean salinity at the study site.

\subsection{Data preparation}

In the laboratory, otoliths were cleaned, embedded in epoxy and sectioned transversally. In turn, Sr concentrations (i.e., Sr concentrations obtained with ${ }^{44} \mathrm{Ca}$ as internal standard) in parts per million (ppm) were measured by LA-ICP-MS at the LA-ICP-MS facility at the Geological Survey of Denmark and Greenland (GEUS) along a transect from the nucleus to the dorsal edge of the otolith following the axis of maximum growth. In the following, the estimated otolith Sr concentrations will be referred to as Sr concentration. Details of the analytical setup and data standardization may be found in Serre et al. (2018) (see also Table S6 and Figure S5). Measurements in the beginning and end of the transect with low ${ }^{44} \mathrm{Ca}$ counts (less than $9 \cdot 10^{6}$ counts per second) were excluded as they represented the Ca concentrations of the epoxy mounts and background. Each data point corresponded to a specific distance to the nucleus. The resulting data represented elemental signatures spanning from hatch to (almost) death of each individual.

Cod otoliths were generally characterized by seasonally varying translucent and opaque zones with concurrent high age estimation precision and well established ageing protocols (Vitale et al., 2019). The width of successive opaque and translucent growth bands, representing annual growth patterns (Hüssy et al., 2016), were measured from nucleus to edge along the laser line-scan using ImageJ (ver. 2 available at https://imagej.net) and counting the number of growth bands provided an estimate of the fish's age. LA-ICP-MS data were thereafter assigned to their respective growth zones of the otolith (Figure 1). Otolith growth zones before the end of the first winter ring were defined as juvenile stages: the larval and demersal juvenile stage from the nucleus to the settling ring, the pelagic juvenile stage from the settling ring to the beginning of the year zero winter ring, and the year zero winter ring. Remaining growth zones were defined as the adult stage.

\subsection{Modelling Sr concentration in the otolith}

Since the data generating process inherently included measurement errors, the chemical element profiles were analysed using a regime-switching state-space model. The model had three layers: the first layer was an unobserved discrete valued process reflecting habitat type preference (similar to the habitat types in Fablet et al., 2007), the second layer was an unobserved real valued process reflecting the true chemical element concentration in the otolith, while the last layer was a real valued process describing the difference between true and observed Sr concentrations in the otolith.

When a fish stayed within a restricted geographical area, and the corresponding salinity was constant, the resulting Sr concentration was assumed to revolve around a constant level. However, throughout its life, a fish could be migrating between different locations, thereby experiencing different salinities resulting in changes in $\mathrm{Sr}$ concentrations. The destination areas of these migrations was referred to as "habitat type preference". The habitat type 


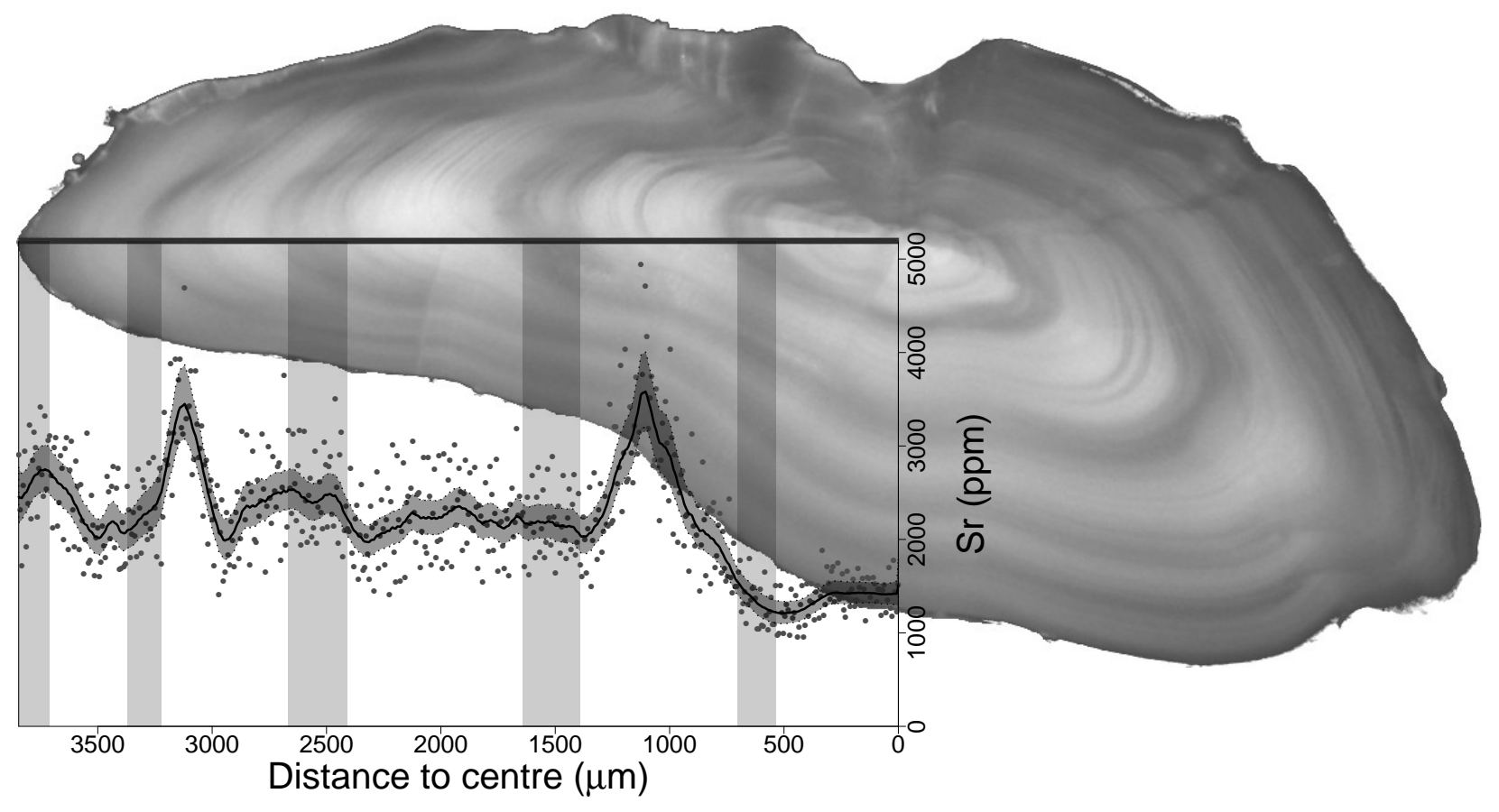

Figure 1: Example of an otolith from a four-year-old Kattegat cod with the corresponding $\mathrm{Sr}$ trajectory. In the graph, shaded areas indicate winter rings, dots indicate measured $\mathrm{Sr}$ concentration, while the full black line and surrounding polygon indicate the reconstructed Sr concentration and a $95 \%$ confidence interval, respectively. The otolith has been cut out and rotated for illustration. The original image is available in the supplementary materials. 
preference reflected, for instance, spawning areas, feeding areas, and general preference. In the study area considered here, four cod stocks, managed in four different areas, were known to be present: North Sea, Kattegat, Western Baltic and Eastern Baltic. Therefore, four habitat type preferences were included to reflect the four areas from the Baltic to the North Sea; however, the method could be used with any number of habitat type preferences.

\subsubsection{First model layer: unobserved habitat type preference}

Similar to Fablet et al. (2007), the first layer of the model was described by a Markov process. In the process, the probability of switching habitat type preference, $S_{i}$, from observation $i-1$ to $i$ was described by the generating matrix $Q$. In $Q$, non-diagonal elements had to be positive, and diagonal elements were fixed to ensure that row sums were zero. From the generating matrix, transition probabilities from observation $i-1$ to $i$ were calculated through the matrix exponential function:

$$
P_{i}=\exp \left(Q \Delta_{i}\right)
$$

where $\Delta_{i}$ was the distance between observation $i-1$ and $i$. For this application, the distance was in otolith length, however, calendar time could be used based on a growth model. The probability of switching from habitat type preference $k$ to habitat type preference $j$ from observation $i-1$ to $i$ was the $k j$ element of $P_{i}$.

\subsubsection{Second model layer: unobserved true chemical element concentration}

Given the habitat type preference, the true unobserved log-Sr concentration, $X_{i}$, was assumed to follow an Ornstein-Uhlenbeck process,

$$
X_{i}=\exp \left(-\beta \Delta_{i}\right)\left(X_{i-1}-\mu_{S_{i}}\right)+\epsilon_{i}
$$

where $\beta>0$ was an autocorrelation parameter, and $\mu_{S_{i}}>0$ was a habitat type dependent mean Sr concentration. Similar to Fablet et al. (2007), $\mu_{S_{i}}$ could be altered to include covariates such as age, season, growth, ontogeny, sex, stress, temperature, feeding rations, or reproductive status, if available, that may affect $\mathrm{Sr}$ concentration in the otolith. Further, $\epsilon_{i}$ was a Gaussian random variable with mean zero and variance

$$
\operatorname{Var}\left(\epsilon_{i}\right)=\frac{\sigma^{2}}{2 \beta}\left(1-\exp \left(-2 \beta \Delta_{i}\right)\right)
$$

For this application, the parameters $\beta$ and $\sigma^{2}$ were assumed to be the same for all habitat type preferences because they were assumed to depend on a generic process of Sr substituting for $\mathrm{Ca}$ in the growing otolith and subsequently extracted by mass spectrometry. In applications where this could not be assumed, separate values could be estimated for the habitat types. Further, if relevant, such assumptions could be tested by likelihood ratio tests. Habitat type preferences reflected Sr concentrations at which the data had plateaus. They corresponded to hypothetical habitat positions; however, if data were not observed around a plateau, a concentration would be estimated from the observed rate of attraction alone. In this case, unusually high or low values might be estimated reflecting the hypothetical nature of the habitat positions. 


\subsubsection{Third model layer: difference between true and observed $\mathrm{Sr}$ concentra- tions}

In the final layer of the model, observed log-concentrations of $\mathrm{Sr}, Y_{i}$, were assumed to follow a normal distribution where the mean was the true $\log$-Sr concentration. That is,

$$
Y_{i}=X_{i}+\nu_{i}
$$

where $\nu_{i}$ was a Gaussian random variable with mean zero and variance $\tau^{2}$.

Parameters were estimated by maximum likelihood using an approximate regime-switching filter (Albertsen, 2018) implemented in R (version 3.6.1, R Core Team, 2019) with the package TMB (Kristensen et al., 2016). Parameters were assumed to be equal for all individuals in an otolith collection. Given the maximum likelihood estimates, the most likely habitat type preference and true Sr concentration processes were reconstructed for each individual using an approximate regime-switching smoother (Albertsen, 2018).

In one otolith collection, growth zone readings were available (see section 'Case study'). For these otoliths, parameters $\left(Q, \beta, \mu_{S_{1}}, \ldots, \mu_{S_{4}}, \sigma^{2}, \tau^{2}\right)$ were assumed to differ between the juvenile and the adult growth zones owing to ontogenetic differences in depth occupation with associated environmental salinities, of these life stages. When growth zones were not available, parameters were estimated as constant throughout the life of a fish. Note that in the present model, such a hypothesis could be tested by, for instance, a likelihood ratio test. For the otolith collection where growth zone readings were not available, the same parameters were used throughout the life of the fish.

\subsection{Modelling the Sr to salinity calibration curve}

In order to relate the reconstructed $\mathrm{Sr}$ concentrations to salinities and, in turn, sea areas, $\mathrm{Sr}$ concentrations at the otolith edges were compared to salinity at the capture positions. Salinity at the capture positions were extracted from Copernicus Marine Environment Monitoring Service Global Ocean 1/12 ${ }^{\circ}$ Physics Analysis and Forecast (Global Monitoring and Forecasting Center, 2019b, Figure S4,). For simplicity, the bottom salinity at each position averaged over the period January 172016 to December 172017 was used. Combining both otolith collections, log-salinity and log-Sr were fitted by a multivariate normal distribution, since both are model outputs. $\log$-salinity $(\log S)$ was assumed to have marginal mean $\mu$ while $\log S r$ was assumed to have marginal mean $\alpha+\rho \frac{\sigma_{S r}}{\sigma_{S}} \mu$ where $\rho$ was a correlation parameter, $\sigma_{S r}$ and $\sigma_{S}$ were the marginal variances of $\mathrm{Sr}$ and salinity, respectively, on log scale. Consequently, for a know salinity, the mean $\log S r$ concentration was linear in $\log S$ :

$$
E(\log S r \mid \log S)=\alpha+\rho \frac{\sigma_{S r}}{\sigma_{S}} \log S
$$

Likewise, for a known $\mathrm{Sr}$ concentration, the expected salinity was

$$
E(\log S \mid \log S r)=\mu+\rho \frac{\sigma_{S}}{\sigma_{S r}}\left(\log S r-\left(\alpha+\rho \frac{\sigma_{S r}}{\sigma_{S}} \mu\right)\right)
$$


To help estimation of the marginal distribution of salinity, every observation of salinity (i.e. from Figure S4) was included. The value of $\mu$ was fixed to $\log (15)$ corresponding to the salinity between Kattegat and the western Baltic Sea. Further, only adult samples were included in the calibration curve estimation. Since the model for $\mathrm{Sr}$ concentrations assumed an ontogenetic difference in Sr concentrations between juveniles and adults, use of the calibration curve on juveniles must be interpreted with caution. Using the resulting conditional distribution of salinity given Sr, full $\mathrm{Sr}$ trajectories were converted to salinity. To propagate uncertainties in the estimates, confidence intervals were based on simulations from normal approximations of the estimators. Based on these samples, the density of salinity values was calculated and illustrated geographically through the known ocean salinity (Figure S4). For simplicity, only salinity and Sr were considered. Thereby, salinity was assumed to be adequate to describe the $\mathrm{Sr}$ concentration. However, if enough samples were available calibration curves could be fitted to account for other factors such as age, season, growth, ontogeny, sex, stress, temperature, feeding rations, or reproductive status. These factors could either be included directly in the log-log linear model, or separate calibration curves could be fitted for each covariate value (e.g., a calibration curve per sex).

Since salinity was only converted to position visually, we could not distinguish between areas with the same salinity. The Eastern Baltic Sea had two areas with high bottom salinity; however, these areas were hypoxic. For simplicity, these areas were not considered in the analysis.

\subsection{Simulation study}

Before turning to the case study, we presented a simulation study to validate the method. The simulation study was intended to show that if the model assumptions were reasonable then the results from the method were reliable.

The simulation study validated the full method in a realistic scenario and included the ability to link reconstructed Sr concentrations to salinity. That is, the data was generated from a more complex model than the estimation model. First, individual fish movement was simulated. Based on the position of the fish, salinity and a corresponding true $\mathrm{Sr}$ concentration were obtained and observed Sr was simulated. Finally, the methods proposed above were applied to the simulated data and the results were compared to the true values: estimated parameter values were compared to the parameter values used for simulation, reconstructed habitat type preferences were compared to simulated habitat type preferences, reconstructed $\mathrm{Sr}$ concentrations were compared to the true simulated $\mathrm{Sr}$ concentrations without measurement error, and reconstructed salinities were compared to the simulated salinities. Further, a simulation study only validating the method for reconstructing $\mathrm{Sr}$ concentrations in the otolith from noisy data was included in the supplementary material.

To fully evaluate the proposed method, a Markov chain of habitat type preferences was simulated. The habitat type preferences corresponded to attraction towards the points: $\left(14.7^{\circ} \mathrm{E}, 54.3^{\circ} \mathrm{N}\right),\left(12.79^{\circ} \mathrm{E}, 55.55^{\circ} \mathrm{N}\right),\left(11.10^{\circ} \mathrm{E}, 56.80^{\circ} \mathrm{N}\right)$, and $\left(9.97^{\circ} \mathrm{E}, 57.98^{\circ} \mathrm{N}\right)$. Given the habitat preferences, geographical positions were simulated along a trajectory connecting the four attraction points successively and extended on both sides (see supplementary Figure S3) . On logit-scale, the position on the trajectory was simulated by a discretized OrnsteinUhlenbeck process where the mean parameter was determined by the attraction point of the 
current habitat type preference and, in turn, converted to a geographical position.

For each simulated geographical position, a corresponding salinity was obtained. Afterwards, salinity measurements were transformed to true simulated log-Sr concentrations by the relation

$$
\log S r=6.33+0.4 \log S .
$$

Finally, log-Sr observations were simulated from a normal distribution with variance $0.05^{2}$ and the true log-Sr concentration as mean. The variance used corresponds to the estimated variance for the second otolith collection in the case study.

In total, 200 otolith collections containing 20 individuals each were simulated. Following the method introduced above, parameters were estimated and Sr concentrations reconstructed for each data set. Afterwards, the Sr-salinity relation was estimated and Sr concentrations were converted to salinity. Finally, parameter estimates were compared to the true values.

\subsection{Case study}

A good case study for illustrating this approach was the Atlantic cod in the area of the Baltic Sea-Kattegat-North Sea. The geographical area had a pronounced environmental salinity gradient, from brackish water in the Baltic Sea to high salinity in the North Sea, and the Atlantic cod was known to undertake migrations between the different salinity regimes contained within the area. Further, the otolith growth zones of Atlantic cod were generally easy to analyze (Vitale et al., 2019). This case study consists of data from two otolith collections.

In the first otolith collection, Atlantic cod were selected from the samples collected during the international Kattegat Survey (KASU) and Sole Survey in December 2016 stratified by area and size to ensure adequate sample sizes from the northern and southern Kattegat within the size ranges $<25 \mathrm{~cm}, 45-55 \mathrm{~cm},>60 \mathrm{~cm}$. Further, samples from the International Bottom Trawl Survey (IBTS) and from monitoring of commercial fisheries were included to extend the geographical range of the samples. From each fish, otoliths were extracted, cleaned of adhering tissue and stored in individually labeled paper bags.

The primary data consisted of Sr trajectories from 342 otoliths. Of these, 139 fish were genetically from the Kattegat stock while 162 were from the North Sea stock (see Nielsen et al. (2012) and Hemmer-Hansen et al. (2019) for a general description of concept and methodology and Hemmer-Hansen et al. (2020) for a specific implementation to Kattegat and North Sea). For the 41 IBTS and commercial samples, genetic information was not available. Fish ages ranged from zero to eight years.

Otolith microchemical data was prone to have outliers. For simplicity, log-observations more than four times the inter quantile range from the median were removed. This procedure removed 17813 observations corresponding to $1.5 \%$ of all measurements.

Capture locations from the surveys represented a narrow range of ocean salinity. Therefore, the case study was supplemented by a second otolith collection which was a subset of the data analyzed in Heidemann et al. (2012). This collection had Sr trajectories from 68 otoliths: 16 from the North Sea stock, 37 from the Eastern Baltic stock, and 15 from the Western Baltic stock. Fish ages ranged from 2 to 6 years. In the second otolith collection, 19765 observations were removed as outliers corresponding to $4.4 \%$. 
For each collection, otoliths were used in combination to obtain maximum likelihood estimates of model parameters. Combining all otoliths in a collection assumed model parameters were shared between individuals; thereby assuming that all parameters reflected population structures rather than individual effects. For the maximum likelihood estimates, Sr concentrations and habitat type preference were reconstructed for each otolith. Parameters were estimated separately for the primary and supplementary otoliths because the analytical settings for the laser ablation instruments and mass spectrometers were different; notably, the beam sizes and line-scan speed differed. Thereby, the scale of autocorrelation and variance parameters differed for the two otolith collections. Afterwards, capture positions and reconstructed Sr concentrations at the otolith edge were related to ocean salinity. This was done for both collections in combination since the salinity range covered by the first collection was too narrow to estimate a relation. Finally, the estimated Sr-salinity relation was used to infer geographical position throughout the life of each individual fish.

\subsection{Salinity-Sr relation compared to other studies}

In order to further evaluate the validity of our approach of estimating salinity based on otolith Sr concentration in this case study, the estimated North Sea/Kattegat/Baltic Sea specific salinity - Sr relationship was compared with published values from laboratory experiments covering a diverse range of species from different habitats around the world (Barnes and Gillanders, 2013; Elsdon and Gillanders, 2002; Hicks et al., 2010; Lin et al., 2007; Martin and Wuenschel, 2006; Miller, 2011; Reis-Santos et al., 2013; Secor et al., 1995; Stanley et al., 2015; Tzeng, 1996; Zimmerman, 2005). The same salinity-Sr model as in the case study was fitted to the data from the literature.

\section{Results}

\subsection{Simulation study}

In the simulation study, Sr concentrations were obtained through simulated fish movement. From the simulated geographical positions, salinities were obtained and converted to $\mathrm{Sr}$ concentrations. For each simulated otolith data set, salinity and Sr concentrations were reconstructed and compared to the simulated truth. In this simulation study, parameter estimates were not of interest since the estimation model did not correspond to the simulation model; however, estimated parameters of the calibration curve were compared to the true values.

\subsubsection{Reconstructed Sr concentrations}

The proposed method performed well in reconstructing Sr concentrations from noisy data. The median difference between recovered and true simulated log-Sr concentrations was calculated for each simulated otolith data set. For the 200 simulations, the average difference was 0.000945 log-ppm. Calculated median differences ranged from - 0.00445 to 0.00472 log-ppm. The median standard deviation of the log-difference was $0.0282 \mathrm{log}$-ppm, corresponding to a coefficient of variation of 0.241 on the reconstructed $\mathrm{Sr}$ concentrations. The smallest standard 
deviation in the simulations was 0.0212 log-ppm. One simulation had large outliers in the reconstructed $\mathrm{Sr}$ concentrations resulting in standard deviations of the difference to the true values of 73876 log-ppm. In the remaining simulations, standard deviations were below 0.12 log-ppm. In a non-automated application, the problematic cases would be easily detected and handled.

As expected, Hessian based 95\% confidence intervals could not provide the expected coverage; that is, fewer than $95 \%$ of the calculated confidence intervals contained the true value. In this simulation study, the estimation model is strongly simplified compared to the simulation model. Consequently, different sources of uncertainty could not be captured correctly. In spite of this, $29 \%$ of the simulations had the correct coverage, $86 \%$ had a coverage above $93 \%$, while $97.5 \%$ of the simulations had a coverage above $90 \%$. In the remaining simulations, the coverage was $0,0.005517,0.009751,0.0152$, and $89.77 \%$, respectively. For the most problematic of these simulations, the calculated standard error of the reconstructed Sr concentrations was effectively zero for a majority of the time series. Therefore, the problem could easily be detected in applications. Again, this indicated that the method could reconstruct Sr concentrations from noisy LA-ICP-MS data, even when the model was a simplification of the true data generating system. While the quality of the reconstruction depends on the data at hand, there were issues with the problematic simulations that would raise attention to a poor fit of the model.

\subsubsection{Calibration curve parameters}

To infer geographical position from otolith chemical compositions, a calibration curve was fitted to convert Sr concentrations to salinities. The calibration curve was fitted by combining the reconstructed Sr concentration at the edge of the simulated otolith with the salinity at the known capture position. In the simulations, the true calibration curve was log-log linear such that $\log S r=6.33+0.4 \log S$. The estimated parameters were close to the true values; however, the intercept was slightly higher than the true value while the slope was slightly lower. The mean of the estimated intercept was 6.34 (standard deviation: 0.0226) while the mean estimated slope was 0.395 (standard deviation: 0.0076). In the 200 simulations, the parameter estimates ranged from 6.29 to 6.42 and 0.372 to 0.413 , respectively. As expected in a linear regression, the estimates were highly negatively correlated with a correlation of -0.959 .

\subsubsection{Reconstructed salinity}

Since the parameters of the calibration curve estimates were close to unbiased, salinities were, in general, accurately recovered from the reconstructed Sr concentrations. On average, the median difference between the true and the reconstructed salinities was $0.0114 \mathrm{psu}$. Excluding the simulations where the coverage of Sr confidence intervals were below $0.02 \%$, more than $32.5 \%$ of the recovered salinities were within $0.5 \mathrm{psu}$ of the true value for all otolith collections. The largest proportion of salinities within $0.5 \mathrm{psu}$ of the true value for an otolith collection was $64.7 \%$. Likewise, between 53.8 and $79.5 \%$ of the salinities were less than 1.0 psu from the true value, while 67.6 to $92.8 \%$ were within 2.0 psu of the true simulated salinity. For

the 4 most problematic simulations, the proportion within $0.5 \mathrm{psu}$ of the true value ranged 
from 36 to $42.6 \%$ while the proportion within 1.0 and 2.0 psu were 57.3 to $67.1 \%$, and 77.6 to $86.6 \%$, respectively.

Confidence intervals for salinities were based on confidence intervals of $\mathrm{Sr}$ concentrations and calibration curve parameters. Consequently, the coverage of $95 \%$ confidence intervals were generally lower than $95 \%$. Of the 200 simulations, 24 had the correct coverage, $74.5 \%$ had a coverage above $93 \%$, while $95.5 \%$ of the simulations had a coverage above $90 \%$. Further, 5 simulations had a coverage between 88 and $90 \%$. The remaining simulations, with problematic Sr concentration confidence intervals, had coverages between 39.6 and 54.2\%.

\subsection{Case study}

In the case study, the proposed method was used to infer life time habitat use from otolith chemical compositions in Atlantic cod. To cover a wide range of ocean salinities, two data sources were used. The model was fitted separately to the two otolith data sets, because data were obtained with different mass spectrometry settings; however, the data sets were combined to fit the calibration curve.

\subsubsection{Calibration curve parameters}

Based on the reconstructed $\mathrm{Sr}$ concentrations closest to the edge of otoliths and salinity at capture positions, a calibration curve was fitted (Figure 2). The curve assumed that $\mathrm{Sr}$ was a $\log$ - $\log$ linear function of salinity. The intercept of the curve was estimated to be 6.24 (standard error: 0.0993) while the slope was estimated to be 0.442 (standard error: 0.0304; Wald test for slope equal to zero p-value: $\left.4.967 \cdot 10^{-48}\right)$. While the slope of the relationship was found to be significant, the residual variance was high $\left(R^{2}\right.$ for the log-log relationship: 0.414). Like in the simulation study, the correlation of the estimator was calculated to be highly negative: -0.991 based on the observed information.

\subsubsection{Estimated habitat type preference salinities}

With the estimated calibration curve, the estimated habitat type $\mathrm{Sr}$ concentrations $\left(\mu_{1}, \mu_{2}, \ldots\right.$, see supplementary material for estimated values) of adult cod in the two otolith collections corresponded to salinities (simulation based 95\% confidence intervals assuming known Sr habitat type concentration in parentheses) of 4.42 (3.73;5.09), 16.4 (15.14;17.36), 30.27 (28.6;31.89), and $35.34(35.34 ; 35.34)$ psu and $4.91(4.16 ; 5.58), 9.93(8.9 ; 10.8), 23.77(22.4 ; 25.04)$, and $35.34(35.34 ; 35.34)$ psu, respectively. For both collections, the lowest estimated habitat type salinities, which were estimated without any assumptions about the study area, corresponded to the salinity in the Eastern Baltic Sea, while the highest level corresponded to the salinity in the North Sea (Figure 3). The two middle levels corresponded to the Central/Western Baltic Sea and Kattegat, respectively. Corresponding geographical extents, accounting for uncertainty in estimated Sr concentrations, were illustrated in Figure 3. The difference between the estimated habitat type salinities in the two otolith collections was a direct effect of the difference between estimated habitat type $\mathrm{Sr}$ concentrations. 


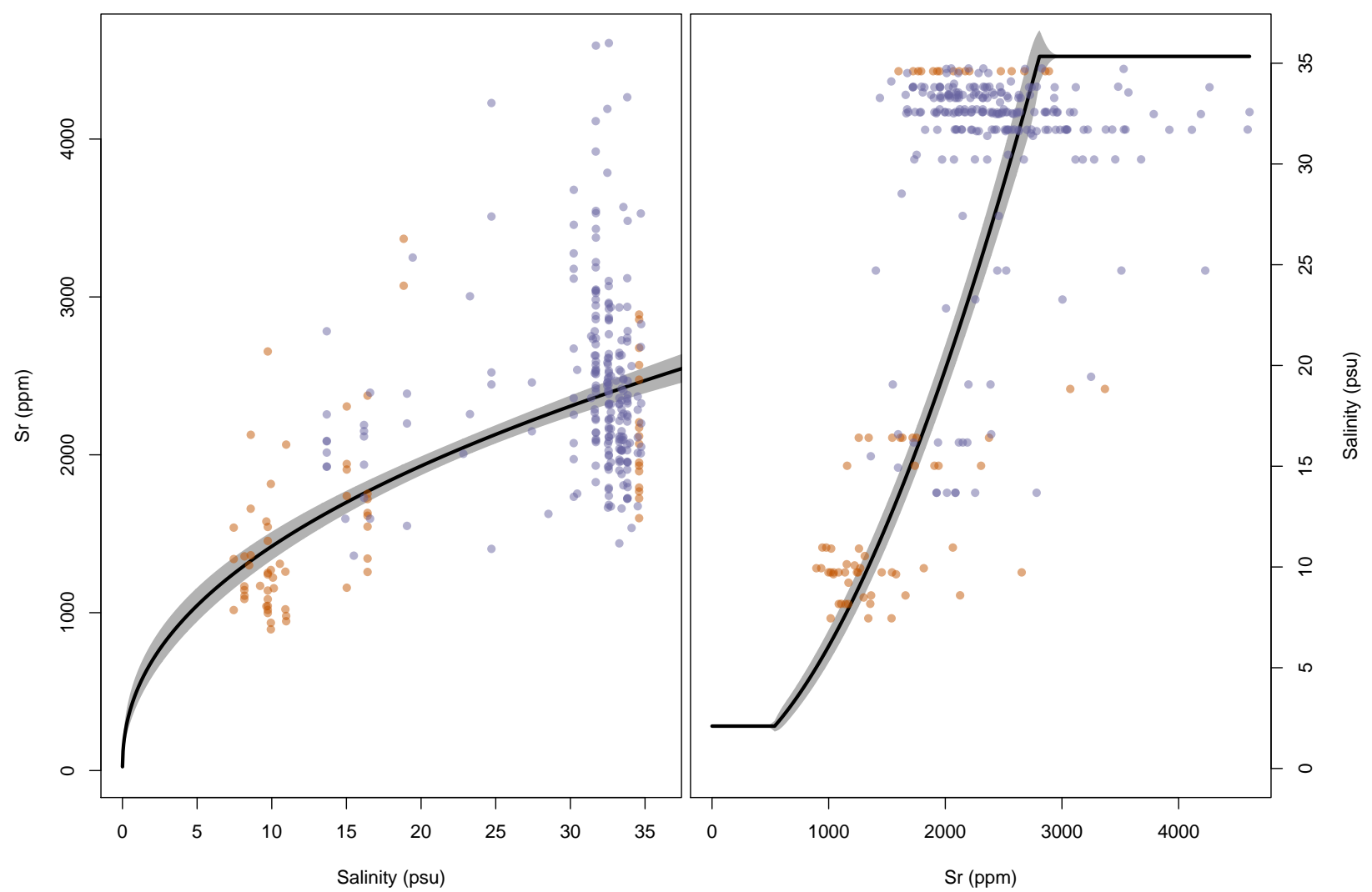

Figure 2: Salinities at capture position and corresponding estimated Sr concentrations at otolith edges from the first (purple) and second (orange) otolith colletions. The estimated $\log -\log$ linear Salinity-Sr relation, $E(\log S r \mid \log S)=6.241+0.442 \log S$, (left panel) and corresponding Sr-salinity relation (right panel) is indicated by the full black line and a $95 \%$ confidence interval by the grey area. Calculated salinity is capped at the lower and upper salinity in the study region. Note that both $\mathrm{Sr}$ and salinity are model output subject to uncertainty. 


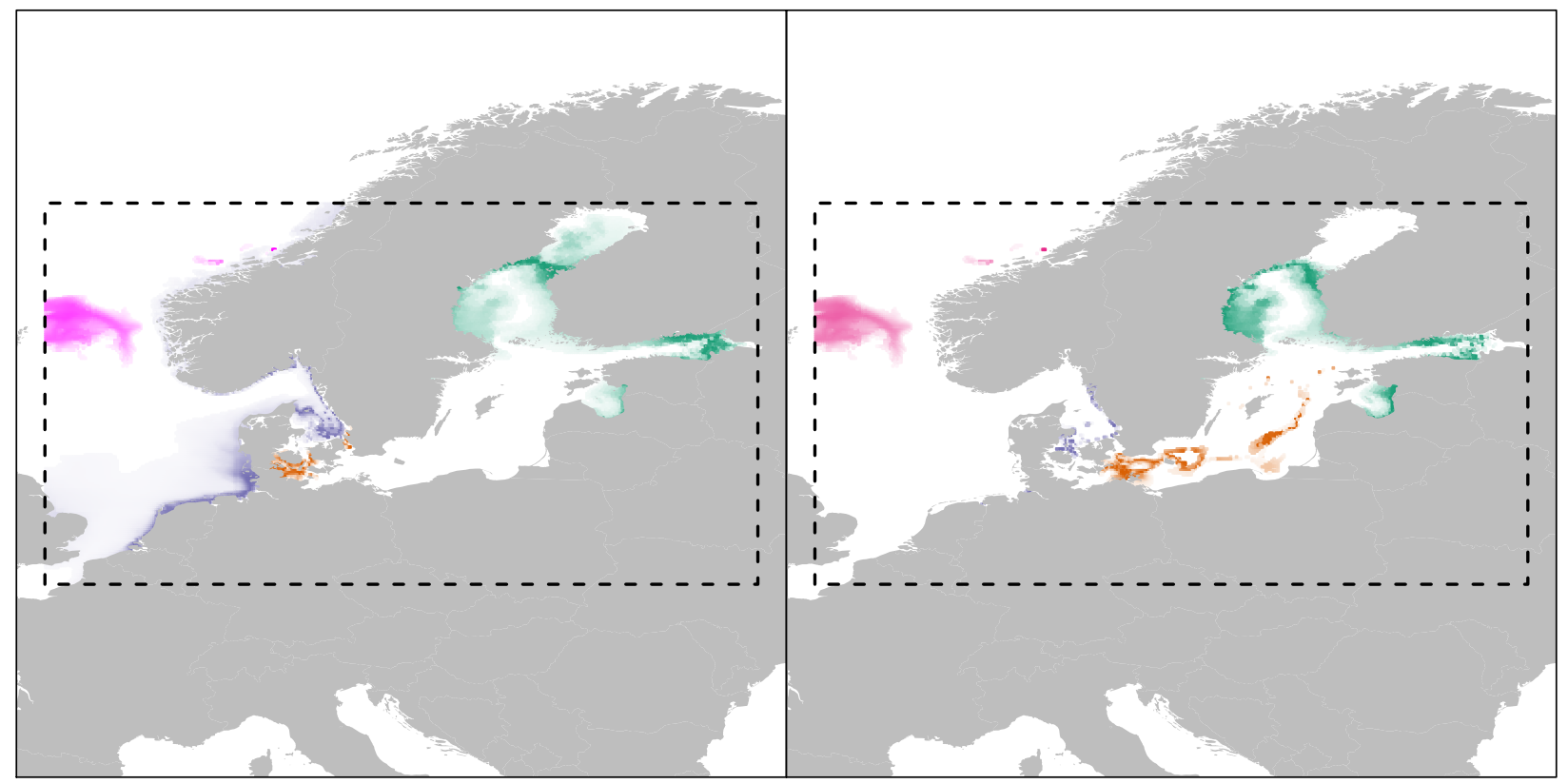

Figure 3: Estimated habitat type Sr concentrations for the first (left panel) and second (right panel) otolith collections translated to salinity. For the first collection, the adult concentrations are shown. The habitat type salinity corresponding to the lowest estimated Sr concentration is shown by a green polygon. The following concentrations are shown by orange and purple polygons, while the salinity corresponding to the highest estimated $\mathrm{Sr}$ concentration is shown by magenta polygons. The map was created using the packages sp (Pebesma and Bivand, 2005; Bivand et al., 2013) and raster (Hijmans, 2018) in R (R Core Team, 2019). Land polygons were made with Natural Earth through the R package rworldxtra (South, 2012). 


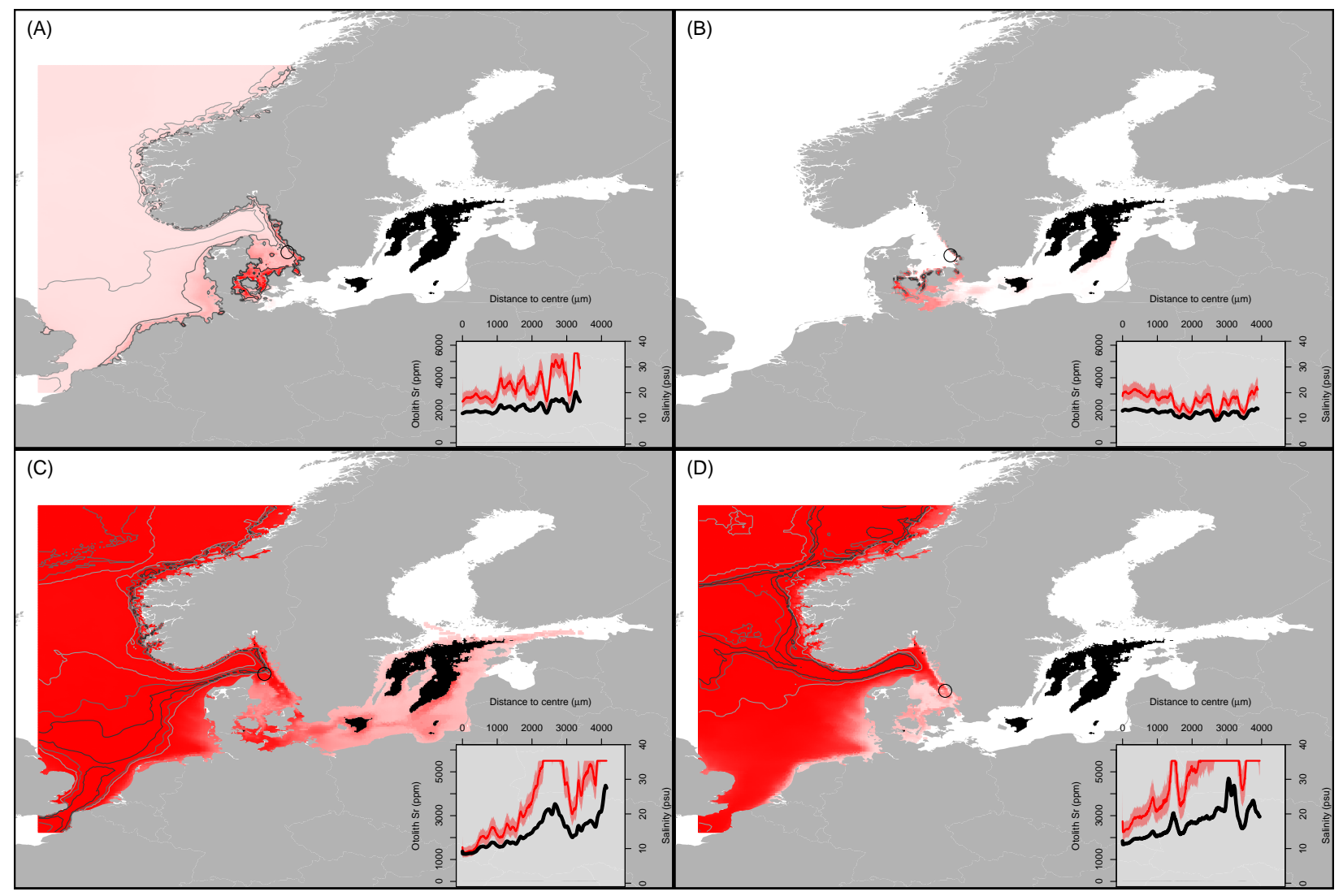

Figure 4: Life time habitat use density inferred from salinity for four Atlantic cod in the first otolith collection from Kattegat (A-B) and the North Sea (C-D). Dark red colors indicate high densities. Further, the graphs in the bottom right corners show estimated Sr (black line, left axis) and salinity (red line, right axis) profiles from hatch to capture. Salinity is capped at the lower and upper salinity in the study region. Hypoxic areas, with oxygen levels below $2 \mathrm{mg} / \mathrm{l}$, are indicated by black polygons (Global Monitoring and Forecasting Center, 2019a). Capture locations are indicated by open circles. The map was created using the packages sp (Pebesma and Bivand, 2005; Bivand et al., 2013) and raster (Hijmans, 2018) in R (R Core Team, 2019). Land polygons were made with Natural Earth through the R package rworldxtra (South, 2012). 


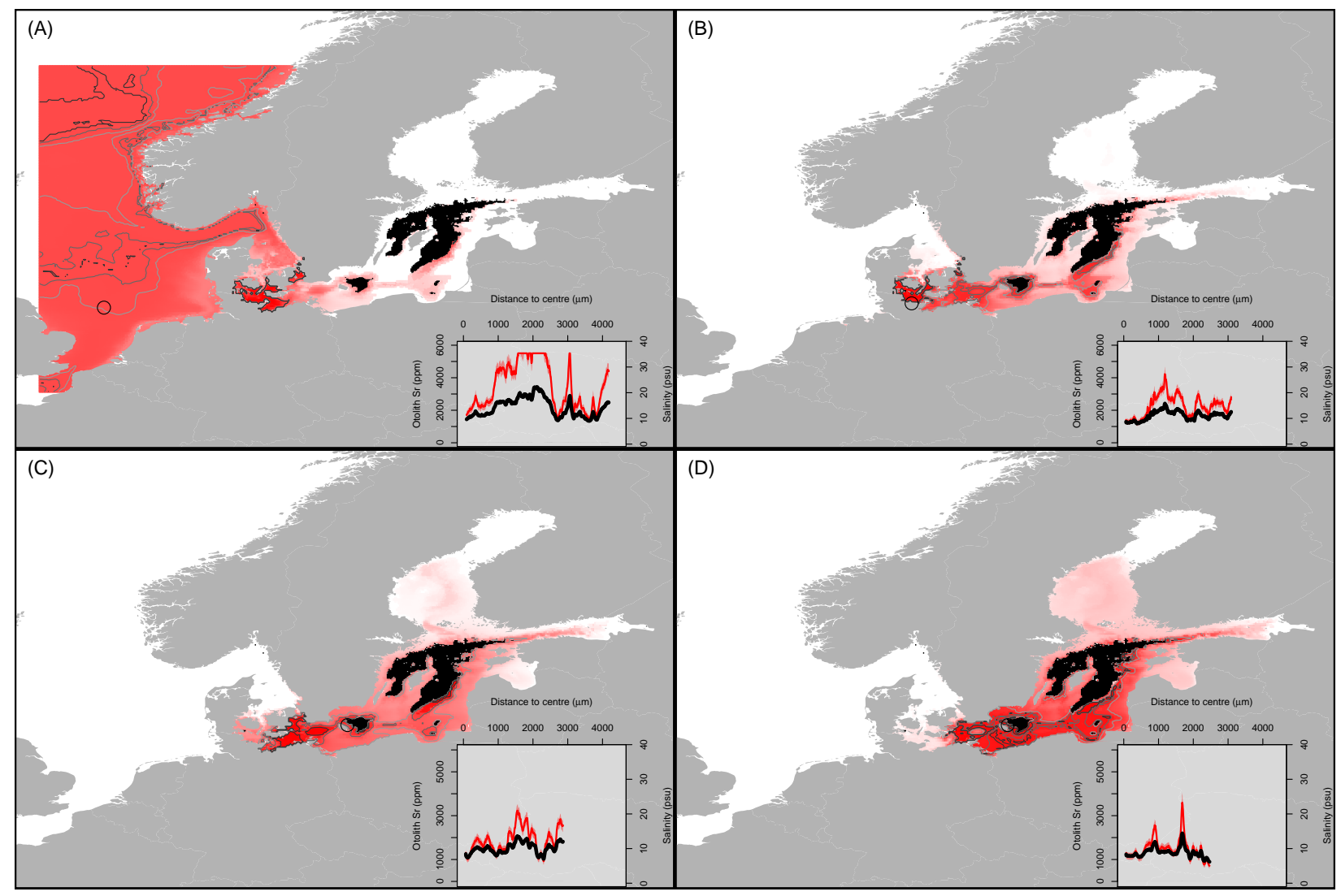

Figure 5: Life time habitat use density inferred from salinity for four cod in the second otolith collection from North Sea (A), Western Baltic (B) and Eastern Baltic (C-D). Dark red colors indicate high densities. Further, the graphs in the bottom right corners show estimated $\mathrm{Sr}$ (black line, left axis) and salinity (red line, right axis) profiles from hatch to capture. Salinity is capped at the lower and upper salinity in the study region. Hypoxic areas, with oxygen levels below $2 \mathrm{mg} / \mathrm{l}$, are indicated by black polygons (Global Monitoring and Forecasting Center, 2019a). Capture locations are indicated by open circles. The map was created using the packages sp (Pebesma and Bivand, 2005; Bivand et al., 2013) and raster (Hijmans, 2018) in $\mathrm{R}$ ( $\mathrm{R}$ Core Team, 2019). Land polygons were made with Natural Earth through the R package rworldxtra (South, 2012). 


\subsubsection{Inferred individual geographical habitat use}

Using the estimated calibration curve, individual reconstructed Sr trajectories were translated to salinities which, in turn, were translated to geographical positions. To translate salinity to geographical position, average salinity from a hydrographical model covering the study area was used. Using the entire Sr trajectory of an individual, the life time habitat use could be mapped. From the newly collected otolith data set, two individuals from the North Sea stock and two individuals from the Kattegat stock were used for illustration (Figure 4).

For the first individual from Kattegat, most of the estimated, most likely, salinities were between 10 and 22 psu, rougly corresponding to the Western Baltic (Figure 4 panel A). For this individual $52.1 \%$ of the estimated salinities were between 10 and $22 \mathrm{psu}$, while $44.7 \%$ were between 22 and 34 psu, roughly corresponding to Kattegat. The final $3.2 \%$ of the estimated salinities were above $34 \mathrm{psu}$, corresponding to Skagerrak/North Sea. In contrast, the second individual from Kattegat had $99.7 \%$ of its estimated salinities between 10 and 22 psu corresponding to a life in the Belt Sea and Sound (Figure 4 panel B). The remaining estimated salinities were between 22 and 34 psu. The two North Sea individuals in the first otolith collection both had a larger proportion of their estimated salinities above $34 \mathrm{psu}$ : $22.6 \%$ and $44.1 \%$, respectively. One of the North Sea individuals had $8.6 \%$ of the estimated salinities below 10, roughly corresponding to the Eastern Baltic Sea, $8.6 \%$ between 10 and 22 psu and $28.7 \%$ between 22 and 34 psu. Note, however, that the number of observations per year decreased with age. Therefore, the proportions could not be directly translated to time. Further, estimated salinities are inherently subject to uncertainty, not accounted for in this tabulation.

From the data set re-analyzed from Heidemann et al. (2012), four individuals were used to illustrate individual estimated habitat use densities: one from the North Sea, one from the Western Baltic, and two from the Eastern Baltic stock (Figure 5). Like the individuals from the first otolith collection, the North Sea individual had $19.6 \%$ of the estimated salinities above $34 \mathrm{psu}$, roughly corresponding to Skagerrak/North Sea. The estimated salinity trajectory indicates that the individual started in low salinity areas before migrating to a high salinity area. Following a period at high salinity, two periods at low salinity were interrupted by a short period at high salinity. Finally, the individual migrated to a high salinity area where it was captured. Therefore, $28.1 \%$ were between 22 and 34 psu, $52.2 \%$ were between 10 and 22 psu, while $0.1 \%$ were below $10 \mathrm{psu}$. In contrast, the Baltic individuals barely had estimated salinity levels above $22 \mathrm{psu}$. For the Western Baltic individual 15.1\% were below 10, $81.7 \%$ were between 10 and 22, while $3.2 \%$ were between 22 and 34 psu. For one Eastern Baltic individual, $81.7 \%$ were between 10 and 22, while $15.1 \%$ were below 10 psu. For the other Eastern Baltic individual, $15.1 \%$ of the estimated salinities were below 10, $81.7 \%$ were between 10 and 22 psu, while the remaining $3.2 \%$ were between 22 and 34 psu. Combined, these eight individuals illustrated a difference in life time habitat use between the four stocks and between individuals from the same stock.

\subsection{Salinity-Sr relation compared to other studies}

As a final validation of the method, the estimated salinity-Sr relation was compared to estimated values from the litterature (Figure 6). Fitting a salinity-Sr relation curve to the 


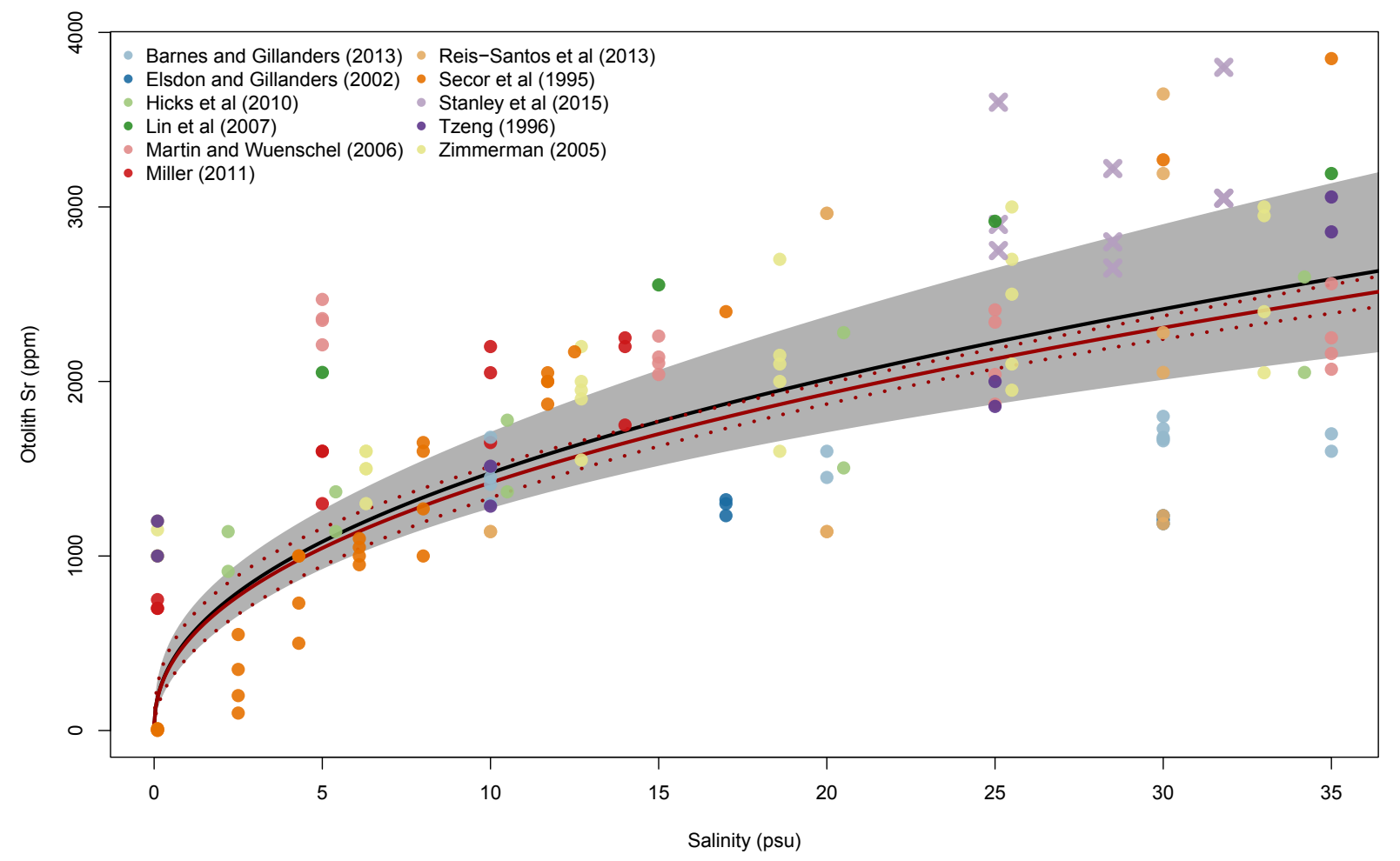

Figure 6: Comparison of fitted log-log linear salinity-Sr relation from the litterature (black line) and this study (red line) with confidence intervals (grey region and dotted red lines, respectively). Points show individual observations from the litterature (Barnes and Gillanders, 2013; Elsdon and Gillanders, 2002; Hicks et al., 2010; Lin et al., 2007; Martin and Wuenschel, 2006; Miller, 2011; Reis-Santos et al., 2013; Secor et al., 1995; Stanley et al., 2015; Tzeng, 1996; Zimmerman, 2005). Observations from cod are shown by a cross while observations from other species are shown by a dot. 
values from the litterature yielded a curve similar to the one obtained in this study. The curve had an estimated intercept of 6.265 and a slope of 0.448 , that is,

$$
E(\log S r \mid \log S)=6.265+0.448 \log S
$$

compared to an intercept and slope of 6.241 and 0.442 , respectively, obtained in this study. Finally, the confidence intervals of the two curves completely overlap (Figure 6).

\section{Discussion}

Habitat use and migration patterns are important information for efficient management and conservation of marine living resources. To this end, otoliths provide an important, and readily available, data source for analysing migration and habitat use patterns. To analyse these patterns, we introduced a method to infer geographical habitat use of individual fish from otolith chemical compositions throughout the life of a fish.

\subsection{Modelling}

While previous studies primarily have focused on documenting spatial or temporal differences between groups of fish, the method introduced here can reconstruct migration patterns of individual fish. The reconstruction is made through a statistical time series model, more specifically a regime-switching state-space model with three layers. The first layer models habitat type preference for the fish, the second layer models the true chemical composition in the otolith, while the final layer models the inherent measurement uncertainty in mass spectrometry data. Subsequently, the reconstructed chemical composition, filtered from measurement uncertainty, is related to geographical areas through a calibration curve. The calibration curve is estimated from data by combining the chemical composition at the edge of the otolith with environmental data at the capture position. The method was validated through a simulation study. The simulation study validated the method in a realistic simulation. Here, fish movement was simulated and strontium concentration was constructed from salinity through a calibration curve. Even in this case, the model provided parameter estimates close to the true values, and was able to reconstruct both salinity and Sr concentrations. Confidence intervals, however, were slightly optimistic. This is expected when data are generated by a more complex process than the estimation model. Further, an additional simulation study, included as supplementary material, validated the estimation method of the time series model. The study showed that the method can re-estimate the parameters and gives correct confidence intervals in the ideal case where data is generated from the estimation model.

\subsection{Model applicability}

To illustrate the applicability of the method, a case study of 342 newly collected Atlantic cod otoliths was presented. Since the newly collected otoliths represented a narrow range of ocean salinity, the data was supplemented by data from Heidemann et al. (2012). The time series model was applied to each otolith collection, while a calibration curve was estimated for the 
collections combined due to the small range of salinities at the capture positions in the new data. The case study provided four important insights that match the current knowledge about the Atlantic cod stocks around Denmark. The estimated habitat use densities indicate that (1) the Eastern Baltic cod stock primarily stays in low salinity areas; (2) the lifetime habitat use of Eastern and Western Baltic stocks are overlapping in space; (3) the North Sea and Kattegat stocks utilize the same areas both in Kattegat, and Skagerrak/North Sea; and (4) the overlap in habitat use between the North Sea stock and the Baltic stocks are limited. Combined with the simulation study, the results of the case study indicate that the method can provide valuable insights into movement and habitat use patterns for other fish stocks in other areas.

\subsection{Model simplifications}

In illustrating the method, several simplifications were made: The nature of observations as a moving average was ignored, salinity was assumed constant over time, hypoxic areas were not considered, and outliers were removed. In the observational model presented here, an observation was assumed to correspond directly to an unobserved true Sr concentration in the otolith. In reality, an observation corresponds to an integral over unobserved Sr concentrations in the otolith. While possible, accounting for this in the model greatly increases the model complexity. Therefore, the estimated Sr concentration must be considered to represent a moving average over the life of an individual.

Several simplifications were made in converting estimated Sr to salinity. Firstly, individuals were assumed to always be at the bottom. Secondly, salinities were averaged over time. Thirdly, the salinity-Sr relation was assumed to be log-log linear and independent of, for instance, age, temperature, season, growth, ontogeny, sex, stress, feeding rations, or reproductive status. The latter may be accounted for in the second model layer, describing the true chemical composition, and in the calibration curve when translating to geographical positions. Several of these assumptions can be relaxed by including in-situ observations of salinity, depth, and temperature from data storage tags. Adding in-situ observation of salinity may, likewise, aid in accounting for temporal changes in salinity from, for example, major Baltic inflows. This will, however, require an extension of the model to account for otolith growth. The 'time scale' of the observations in this study is otolith length. In contrast, data from tags are accumulated in calendar time. Therefore, a growth model is needed to combine the two data sources. When interpreting the calculated salinities as geographical positions, different geographical positions with similar salinity can not be separated. Therefore, the current implementation can not differentiate between, for instance, coastal and off-shore regions with similar salinity. Likewise, a hypoxic area of the Baltic Sea has a high salinity that could not be differentiated from other areas. When illustrating the presented method, the hypoxic area was removed. Alternatively, additional elements may be included to distinguish different areas with similar salinity. Again, this adds to the computational complexity and requires a multi-dimensional calibration curve. Further, it requires that the capture position adequately covers the range of, for instance, potential distances to the shore and oxygen levels. Finally, the approach used here does not fully account for the natural variability in observed Sr-salinity relationship reflected in Figure 2. This variability may be reduced by including other factors affecting the Sr concentration in the otolith such as age, season, growth, ontogeny, sex, stress, temperature, 
feeding rations, or reproductive status (e.g., Sturrock et al., 2015; Hüssy et al., 2020), if available. If the method is used for classification to areas or stocks, an estimation of power would require a cross-validation approach on the full method applied on real observations to investigate how often the correct salinity can be inferred from observed $\mathrm{Sr}$ in the otoliths. This work is beyond the scope of the current study, but can be included in future work using data from more individuals collected from the study regions included in our case study.

In our study, outliers were removed from the data. In general, it is preferable to include outliers with a suitable heavy tailed distribution when possible. This may, however, require additional computational power. Despite these model simplifications, the method is able to illustrate differences in life time habitat use between individuals and stocks. Further research and data is needed to include the additional model complexity discussed here.

\subsection{Proxies for environmental conditions}

There are a number requirements that need to be met for an element to be a good proxy for estimating environmental conditions: The concentrations incorporated into the otolith must reflect environmental conditions, and the incorporation dynamics must neither change over the fish's life, not be subject to seasonal and/or temperature effects. Otolith Sr concentration is known to be strongly correlated with environmental Sr concentration and salinity (Bath et al., 2000; Elsdon and Gillanders, 2003, 2004, 2005a; Kraus and Secor, 2004; Miller, 2011). The estimated relationship between otolith $\mathrm{Sr}$ and environmental salinity in the North Sea Kattegat - Baltic Sea complex is no exception. The relationship estimated here is similar to published values (Figure 6), thereby lending this approach the necessary credibility. Neither temperature (Gallahar, 1996; Kalish, 1989; Reis-Santos et al., 2013; Secor et al., 1995; Tzeng, 1996; Walther et al., 2010) nor growth (Bath et al., 2000; DiMaria et al., 2010; Kalish, 1989; Secor et al., 1995) seem to have a consistent effect on otolith Sr incorporation. While laboratory experiments have suggested that the Sr incorporation dynamics do not change over a fish's life (Begg et al., 2005; Elsdon and Gillanders, 2005b; Fowler et al., 1995), an increase in otolith $\mathrm{Sr}$ concentration is often observed with fish age field in samples of marine species (Hughes et al., 2016; Kalish, 1989). While, for instance, ontogeny, age, and growth may influence incorporation dynamics (e.g., Sturrock et al., 2015; Hüssy et al., 2020), increases with age are usually environmental signals linked to migrations rather than an ontogenetic effect (Sadovy and Severin, 1992; Secor and Rooker, 2000; See, e.g, Hüssy et al., 2020, for a recent review). In this study an apparently ontogenetic change from juvenile to adult fish occurred, with lower otolith Sr during the early life stages. This seems related to an ontogenetic change in habitat occupation from low salinity shallow water in juvenile cod to deeper more saline areas in adult fish in this area (Bauer et al., 2010; Oeberst, 2008; Pihl, 1993).

$\mathrm{Sr}$ is not the only candidate worth considering. Barium (Ba) for example shows a nutrientlike distribution with depletion in coastal and surface waters (Elsdon and Gillanders, 2005a; Walther and Limburg, 2012), while manganese (Mn) is a reliable indicator for environmental hypoxia (Altenritter et al., 2018; Limburg et al., 2011, 2015). Likewise, sources of heavy metal contamination may be useful if there is a gradient in concentration away from the source (Ranaldi and Gagnon, 2008). Common for these possible cases is that they are based on elements and conditions that provide an environmental and biological meaningful 
interpretation.

\subsection{Methodological considerations}

In this study, the calibration curve was estimated in a post-hoc analysis to include both otolith collections in the estimation. This was necessary due to the short range of salinities at the capture positions in the new collection. To obtain a reliable calibration curve, a wide range of values must be present for the environmental variable; that is, otoliths must be collected from the entire study area. Using model output in a post-hoc analysis may create bias; however, the second simulation study showed that the method could provide calibration curve parameter close to the true values. Further, it was assumed that the same calibration curve could be used throughout the life of an individual. If this is not a reasonable assumption, a calibration curve including, for instance, fish age as a covariate can be estimated instead. Likewise, the time series model assumed that there is no lag in Sr deposition in the otolith and that the $\mathrm{Sr}$ concentration is constant if the fish is exposed to a constant salinity. If this is not the case for the relevant trace element, both the time series model and the calibration curve need to be modified to account for these issues; however, estimating a time lag in trace element incorporation will likely require additional data or explicitly including the processes included in incorporating the element in the otolith.

Finally, the present model ignores the change in time scale through the life of a fish. In the model, distance from the otolith nucleus is used as the time scale; however, as the fish ages, the growth rate decreases, both for the fish and the otolith. Therefore, the same distance in the otolith corresponds to different time differences in the beginning and the end of the otolith. Moreover, observations correspond to an average over time where the time interval is determined by the constant beam size, thereby reflecting different time scales from the nucleus to the edge of the otolith. Further research is needed to include this change in time scale through a growth model; however, a straight forward approach could be to transform the time scale independently of the methods presented here (e.g., Morissette et al., 2016; Gallagher et al., 2018). When investigating the time spend in different habitats, even a simple approach to transforming the time scale may be preferable over the measured transect lengths.

Analysing otolith chemical compositions by time series models will greatly improve the usefulness of the data. Through time series models, as the method introduced here, individuals can not only be classified to stocks of origin, their entire life history can be investigated. Investigating, explaining, and comparing migration and habitat use patterns of different stocks provides invaluable input for conservation and management of marine living resources. For Atlantic cod, strontium-salinity was the relevant relation from otolith to environment; however, the method outlined is directly applicable for other trace elements and study areas.

\section{Acknowledgements}

This study has been conducted using E.U. Copernicus Marine Service Information. The authors thank Benjamin Dominguez Heredia (Geological Survey of Denmark and Greenland) for assistance with measuring the accuracy and precision of measured internal standards 
and for preparing Figure S4. Further, the authors would like to thank the two anonymous reviewers for comments to improve the presentation of this manuscript.

\section{References}

Albertsen, C. M. (2018). State-space modelling in marine science, chapter An approximate filter and smoother for general regime-switching state-space models. Technical University of Denmark, National Institute of Aquatic Resources.

Albuquerque, C. Q., Miekeley, N., Muelbert, J. H., Walther, B. D., and Jaureguizar, A. J. (2012). Estuarine dependency in a marine fish evaluated with otolith chemistry. Marine Biology, 159(10):2229-2239, doi:10.1007/s00227-012-2007-5.

Altenritter, M., Cohuo, A., and Walther, B. (2018). Proportions of demersal fish exposed to sublethal hypoxia revealed by otolith chemistry. Marine Ecology Progress Series, 589:193208, doi:10.3354/meps12469.

Barnes, T. C. and Gillanders, B. M. (2013). Combined effects of extrinsic and intrinsic factors on otolith chemistry: implications for environmental reconstructions. Canadian Journal of Fisheries and Aquatic Sciences, 70(8):1159-1166, doi:10.1139/cjfas-2012-0442.

Bath, G. E., Thorrold, S. R., Jones, C. M., Campana, S. E., McLaren, J. W., and Lam, J. W. (2000). Strontium and barium uptake in aragonitic otoliths of marine fish. Geochimica et Cosmochimica Acta, 64(10):1705-1714, doi:10.1016/s0016-7037(99)00419-6.

Bauer, R., Stepputtis, D., Storr-Paulsen, M., Weigelt, R., and Hammer, C. (2010). Estimating abundances of 0 -group western baltic cod by using pound net fisheries. Informationen aus der Fischereiforschung, 57(1):1-11, doi:10.3220/Infn57_1-11_2010.

Begg, G. A., Campana, S. E., Fowler, A. J., and Suthers, I. M. (2005). Otolith research and application: current directions in innovation and implementation. Marine and Freshwater Research, 56(5):477, doi:10.1071/mf05111.

Bivand, R. S., Pebesma, E., and Gomez-Rubio, V. (2013). Applied spatial data analysis with $R$, Second edition. Springer, NY.

Campana, S. E., Chouinard, G. A., Hanson, J. M., and Fréchet, A. (1999). Mixing and migration of overwintering atlantic cod (gadus morhua) stocks near the mouth of the gulf of st. lawrence. Canadian Journal of Fisheries and Aquatic Sciences, 56(10):1873-1881, doi:10.1139/f99-083.

Cappo, M., De'ath, G., Boyle, S., Aumend, J., Olbrich, R., Hoedt, F., Perna, C., and Brunskill, G. (2005). Development of a robust classifier of freshwater residence in barramundi (lates calcarifer) life histories using elemental ratios in scales and boosted regression trees. Marine and Freshwater Research, 56(5):713, doi:10.1071/mf04218. 
DiMaria, R. A., Miller, J. A., and Hurst, T. P. (2010). Temperature and growth effects on otolith elemental chemistry of larval pacific cod, gadus macrocephalus. Environmental Biology of Fishes, 89(3-4):453-462, doi:10.1007/s10641-010-9665-2.

Edmonds, J. S., Moran, M. J., Caputi, N., and Morita, M. (1989). Trace element analysis of fish sagittae as an aid to stock identifications: Pink snapper (chrysophrys auratus) in western australian waters. Canadian Journal of Fisheries and Aquatic Sciences, 46(1):50-54, doi:10.1139/f89-007.

Elsdon, T. S. and Gillanders, B. M. (2002). Interactive effects of temperature and salinity on otolith chemistry: challenges for determining environmental histories of fish. Canadian Journal of Fisheries and Aquatic Sciences, 59(11):1796-1808, doi:10.1139/f02-154.

Elsdon, T. S. and Gillanders, B. M. (2003). Relationship between water and otolith elemental concentrations in juvenile black bream acanthopagrus butcheri. Marine Ecology Progress Series, 260:263-272, doi:10.3354/meps260263.

Elsdon, T. S. and Gillanders, B. M. (2004). Fish otolith chemistry influenced by exposure to multiple environmental variables. Journal of Experimental Marine Biology and Ecology, 313(2):269-284, doi:10.1016/j.jembe.2004.08.010.

Elsdon, T. S. and Gillanders, B. M. (2005a). Alternative life-history patterns of estuarine fish: barium in otoliths elucidates freshwater residency. Canadian Journal of Fisheries and Aquatic Sciences, 62(5):1143-1152, doi:10.1139/f05-029.

Elsdon, T. S. and Gillanders, B. M. (2005b). Consistency of patterns between laboratory experiments and field collected fish in otolith chemistry: an example and applications for salinity reconstructions. Marine and Freshwater Research, 56(5):609, doi:10.1071/mf04146.

Fablet, R., Daverat, F., and De Pontual, H. (2007). Unsupervised bayesian reconstruction of individual life histories from otolith signatures: case study of sr:ca transects of european eel (anguilla anguilla) otoliths. Canadian Journal of Fisheries and Aquatic Sciences, 64(1):152-165, doi:10.1139/f06-173.

Fowler, A. J., Campana, S. E., Thorrold, S. R., and Jones, C. M. (1995). Experimental assessment of the effect of temperature and salinity on elemental composition of otoliths using solution-based ICPMS. Canadian Journal of Fisheries and Aquatic Sciences, 52(7):1421-1430, doi:10.1139/f95-137.

Gallagher, B. K., Piccoli, P. M., and Secor, D. H. (2018). Ecological carryover effects associated with partial migration in white perch (morone americana) within the hudson river estuary. Estuarine, Coastal and Shelf Science, 200:277-288, doi:10.1016/j.ecss.2017.11.011.

Gallahar, N. (1996). Factors influencing sr / ca ratios in otoliths ofGirella elevata: an experimental investigation. Journal of Fish Biology, 48(2):174-186, doi:10.1006/jfbi.1996.0018.

Gibb, F. M., Régnier, T., Donald, K., and Wright, P. J. (2017). Connectivity in the early life history of sandeel inferred from otolith microchemistry. Journal of Sea Research, 119:8-16, doi:10.1016/j.seares.2016.10.003. 
Global Monitoring and Forecasting Center (2019a). Baltic Sea Biogeochemistry Reanalysis Product, E.U. Copernicus Marine Service Information [Data set]. Accessed: 19th March 2019.

Global Monitoring and Forecasting Center (2019b). Global Ocean 1/12 Physics Analysis and Forecast updated Daily Product, E. U. Copernicus Marine Service Information [Data set]. Accessed: 19th March 2019.

Grammer, G. L., Morrongiello, J. R., Izzo, C., Hawthorne, P. J., Middleton, J. F., and Gillanders, B. M. (2017). Coupling biogeochemical tracers with fish growth reveals physiological and environmental controls on otolith chemistry. Ecological Monographs, 87(3):487-507, doi:10.1002/ecm.1264.

Hamer, P. A., Jenkins, G. P., and Coutin, P. (2006). Barium variation in pagrus auratus (sparidae) otoliths: A potential indicator of migration between an embayment and ocean waters in south-eastern australia. Estuarine, Coastal and Shelf Science, 68(3-4):686-702, doi:10.1016/j.ecss.2006.03.017.

Hedger, R. D., Atkinson, P. M., Thibault, I., and Dodson, J. J. (2008). A quantitative approach for classifying fish otolith strontium: Calcium sequences into environmental histories. Ecological Informatics, 3(3):207-217, doi:10.1016/j.ecoinf.2008.04.001.

Heidemann, F., Marohn, L., Hinrichsen, H., Huwer, B., Hüssy, K., Klügel, A., Böttcher, U., and Hanel, R. (2012). Suitability of otolith microchemistry for stock separation of baltic cod. Marine Ecology Progress Series, 465:217-226, doi:10.3354/meps09922.

Hemmer-Hansen, J., Hüssy, K., Vinther, M., Albertsen, C., Storr-Paulsen, M., and Eero, M. (2020). Sustainable management of kattegat cod; better knowledge of stock components and migration. DTU Aqua Report 357-2020, National Institute of Aquatic Resources, Technical University of Denmark.

Hemmer-Hansen, J., Hüssy, K., Baktoft, H., Huwer, B., Bekkevold, D., Haslob, H., Herrmann, J.-P., Hinrichsen, H.-H., Krumme, U., Mosegaard, H., Nielsen, E. E., Reusch, T. B. H., Storr-Paulsen, M., Velasco, A., von Dewitz, B., Dierking, J., and Eero, M. (2019). Genetic analyses reveal complex dynamics within a marine fish management area. Evolutionary Applications, 12(4):830-844, doi:10.1111/eva.12760.

Hicks, A. S., Closs, G. P., and Swearer, S. E. (2010). Otolith microchemistry of two amphidromous galaxiids across an experimental salinity gradient: A multi-element approach for tracking diadromous migrations. Journal of Experimental Marine Biology and Ecology, 394(1-2):86-97, doi:10.1016/j.jembe.2010.07.018.

Hijmans, R. J. (2018). raster: Geographic Data Analysis and Modeling. R package version 2.8-4.

Hughes, J. M., Stewart, J., Gillanders, B. M., Collins, D., and Suthers, I. M. (2016). Relationship between otolith chemistry and age in a widespread pelagic teleost arripis trutta: influence of adult movements on stock structure and implications for management. Marine and Freshwater Research, 67(2):224, doi:10.1071/mf14247. 
Hüssy, K., Andersen, N. G., and Pedersen, E. M. (2016). The influence of feeding behaviour on growth of atlantic cod (gadus morhua, linnaeus, 1758) in the north sea. Journal of Applied Ichthyology, 32(5):928-937, doi:10.1111/jai.13160.

Hüssy, K., Limburg, K. E., de Pontual, H., Thomas, O. R. B., Cook, P. K., Heimbrand, Y., Blass, M., and Sturrock, A. M. (2020). Trace element patterns in otoliths: The role of biomineralization. Reviews in Fisheries Science \& Aquaculture, pages 1-33, doi:10.1080/23308249.2020.1760204.

Jessop, B., Cairns, D., Thibault, I., and Tzeng, W. (2008). Life history of american eel anguilla rostrata: new insights from otolith microchemistry. Aquatic Biology, 1:205-216, doi:10.3354/ab00018.

Jessop, B., Shiao, J., Iizuka, Y., and Tzeng, W. (2002). Migratory behaviour and habitat use by american eels anguilla rostrata as revealed by otolith microchemistry. Marine Ecology Progress Series, 233:217-229, doi:10.3354/meps233217.

Kalish, J. M. (1989). Otolith microchemistry: validation of the effects of physiology, age and environment on otolith composition. Journal of Experimental Marine Biology and Ecology, 132(3):151-178, doi:10.1016/0022-0981(89)90126-3.

Kennedy, B. P., Klaue, A., Blum, J. D., Folt, C. L., and Nislow, K. H. (2002). Reconstructing the lives of fish using sr isotopes in otoliths. Canadian Journal of Fisheries and Aquatic Sciences, 59(6):925-929, doi:10.1139/f02-070.

Kraus, R. T. and Secor, D. H. (2004). Incorporation of strontium into otoliths of an estuarine fish. Journal of Experimental Marine Biology and Ecology, 302(1):85-106, doi:10.1016/j.jembe.2003.10.004.

Kristensen, K., Nielsen, A., Berg, C. W., Skaug, H., and Bell, B. M. (2016). TMB: Automatic differentiation and Laplace approximation. Journal of Statistical Software, 70(5):1-21, doi:10.18637/jss.v070.i05.

Limburg, K. (1995). Otolith strontium traces environmental history of subyearling american shad alosa sapidissima. Marine Ecology Progress Series, 119:25-35, doi:10.3354/meps119025.

Limburg, K. E., Olson, C., Walther, Y., Dale, D., Slomp, C. P., and Hoie, H. (2011). Tracking baltic hypoxia and cod migration over millennia with natural tags. Proceedings of the National Academy of Sciences, 108(22):E177-E182, doi:10.1073/pnas.1100684108.

Limburg, K. E., Walther, B. D., Lu, Z., Jackman, G., Mohan, J., Walther, Y., Nissling, A., Weber, P. K., and Schmitt, A. K. (2015). In search of the dead zone: Use of otoliths for tracking fish exposure to hypoxia. Journal of Marine Systems, 141:167-178, doi:10.1016/j.jmarsys.2014.02.014.

Lin, S.-H., Chang, C.-W., Iizuka, Y., and Tzeng, W.-N. (2007). Salinities, not diets, affect strontium/calcium ratios in otoliths of anguilla japonica. Journal of Experimental Marine Biology and Ecology, 341(2):254-263, doi:10.1016/j.jembe.2006.10.025. 
Loewen, T. N., Reist, J. D., Yang, P., Koleszar, A., Babaluk, J. A., Mochnacz, N., and Halden, N. M. (2015). Discrimination of northern form dolly varden char (salvelinus malma malma) stocks of the north slope, yukon and northwest territories, canada via otolith trace elements and 87sr/86sr isotopes. Fisheries Research, 170:116-124, doi:10.1016/j.fishres.2015.05.025.

Martin, G. and Wuenschel, M. (2006). Effect of temperature and salinity on otolith element incorporation in juvenile gray snapper lutjanus griseus. Marine Ecology Progress Series, 324:229-239, doi:10.3354/meps324229.

Mercier, L., Mouillot, D., Bruguier, O., Vigliola, L., and Darnaude, A. (2012). Multi-element otolith fingerprints unravel sea-lagoon lifetime migrations of gilthead sea bream sparus aurata. Marine Ecology Progress Series, 444:175-194, doi:10.3354/meps09444.

Miller, J. (2011). Effects of water temperature and barium concentration on otolith composition along a salinity gradient: Implications for migratory reconstructions. Journal of Experimental Marine Biology and Ecology, 405(1-2):42-52, doi:10.1016/j.jembe.2011.05.017.

Morissette, O., Lecomte, F., Verreault, G., Legault, M., and Sirois, P. (2016). Fully equipped to succeed: Migratory contingents seen as an intrinsic potential for striped bass to exploit a heterogeneous environment early in life. Estuaries and Coasts, 39(2):571-582, doi:10.1007/s12237-015-0015-7.

Nielsen, E. E., , Cariani, A., Aoidh, E. M., Maes, G. E., Milano, I., Ogden, R., Taylor, M., Hemmer-Hansen, J., Babbucci, M., Bargelloni, L., Bekkevold, D., Diopere, E., Grenfell, L., Helyar, S., Limborg, M. T., Martinsohn, J. T., McEwing, R., Panitz, F., Patarnello, T., Tinti, F., Houdt, J. K. J. V., Volckaert, F. A. M., Waples, R. S., and Carvalho, G. R. (2012). Gene-associated markers provide tools for tackling illegal fishing and false eco-certification. Nature Communications, 3(1), doi:10.1038/ncomms1845.

Oeberst, R. (2008). Distribution pattern of cod and flounder in the baltic sea based on international coordinated trawl surveys. ICES CM 2008/J:09.

Pebesma, E. J. and Bivand, R. S. (2005). Classes and methods for spatial data in R. R News, $5(2): 9-13$.

Pihl, L. (1993). Migration pattern of juvenile cod (gadus morhua) on the swedish west coast. ICES Journal of Marine Science, 50(1):63-70, doi:10.1006/jmsc.1993.1007.

R Core Team (2019). R: A Language and Environment for Statistical Computing. $\mathrm{R}$ Foundation for Statistical Computing, Vienna, Austria.

Ranaldi, M. M. and Gagnon, M. M. (2008). Trace metal incorporation in otoliths of black bream (acanthopagrus butcheri munro), an indicator of exposure to metal contamination. Water, Air, and Soil Pollution, 194(1-4):31-43, doi:10.1007/s11270-008-9696-x.

Reis-Santos, P., Tanner, S. E., Elsdon, T. S., Cabral, H. N., and Gillanders, B. M. (2013). Effects of temperature, salinity and water composition on otolith elemental incorporation of dicentrarchus labrax. Journal of Experimental Marine Biology and Ecology, 446:245-252, doi:10.1016/j.jembe.2013.05.027. 
Roberts, B. H., Morrongiello, J. R., King, A. J., Morgan, D. L., Saunders, T. M., Woodhead, J., and Crook, D. A. (2019). Migration to freshwater increases growth rates in a facultatively catadromous tropical fish. Oecologia, 191(2):253-260, doi:10.1007/s00442-019-04460-7.

Sadovy, Y. and Severin, K. (1992). Trace-elements in biogenic aragonite - correlation of body growth-rate and strontium levels in the otoliths of the white grunt, haemulon-plumieri (pisces, haemulidae). Bulletin of Marine Science, 50(2):237-257.

Sakamoto, T., Komatsu, K., Shirai, K., Higuchi, T., Ishimura, T., Setou, T., Kamimura, Y., Watanabe, C., and Kawabata, A. (2018). Combining microvolume isotope analysis and numerical simulation to reproduce fish migration history. Methods in Ecology and Evolution, 10(1):59-69, doi:10.1111/2041-210x.13098.

Secor, D. H., Henderson-Arzapalo, A., and Piccoli, P. (1995). Can otolith microchemistry chart patterns of migration and habitat utilization in anadromous fishes? Journal of Experimental Marine Biology and Ecology, 192(1):15-33, doi:10.1016/0022-0981(95)00054-u.

Secor, D. H. and Piccoli, P. M. (1996). Age- and sex-dependent migrations of striped bass in the hudson river as determined by chemical microanalysis of otoliths. Estuaries, 19(4):778, doi: $10.2307 / 1352297$.

Secor, D. H. and Rooker, J. R. (2000). Is otolith strontium a useful scalar of life cycles in estuarine fishes? Fisheries Research, 46(1-3):359-371, doi:10.1016/s0165-7836(00)00159-4.

Seeley, M. and Walther, B. (2018). Facultative oligohaline habitat use in a mobile fish inferred from scale chemistry. Marine Ecology Progress Series, 598:233-245, doi:10.3354/meps12223.

Seeley, M. E., Logan, W. K., and Walther, B. D. (2017). Consistency of elemental and isotope-ratio patterns across multiple scales from individual fish. Journal of Fish Biology, 91(3):928-946, doi:10.1111/jfb.13392.

Serre, S., Nielsen, K., Fink-Jensen, P., Thomsen, T., and Hüssy, K. (2018). Analysis of cod otolith microchemistry by continuous line transects using LA-ICP-MS. Geological Survey of Denmark and Greenland Bulletin, 41:91-94.

South, A. (2012). rworldxtra: Country boundaries at high resolution. R package version 1.01.

Stanley, R. R. E., Bradbury, I. R., DiBacco, C., Snelgrove, P. V. R., Thorrold, S. R., and Killen, S. S. (2015). Environmentally mediated trends in otolith composition of juvenile atlantic cod (gadus morhua). ICES Journal of Marine Science: Journal du Conseil, 72(8):2350-2363, doi:10.1093/icesjms/fsv070.

Sturrock, A. M., Hunter, E., Milton, J. A., Johnson, R. C., Waring, C. P., and and, C. N. T. (2015). Quantifying physiological influences on otolith microchemistry. Methods in Ecology and Evolution, 6(7):806-816, doi:10.1111/2041-210x.12381.

Sturrock, A. M., Trueman, C. N., Darnaude, A. M., and Hunter, E. (2012). Can otolith elemental chemistry retrospectively track migrations in fully marine fishes? Journal of Fish Biology, 81(2):766-795, doi:10.1111/j.1095-8649.2012.03372.x. 
Tzeng, W.-N. (1996). Effects of salinity and ontogenetic movements on strontium:calcium ratios in the otoliths of the japanese eel, anguilla japonica temminck and schlegel. Journal of Experimental Marine Biology and Ecology, 199(1):111-122, doi:10.1016/0022-0981(95)001859.

Vitale, F., Worsøe Clausen, L., and Ní Chonchúir, G. (2019). Handbook of fish age estimation protocols and validation methods. ICES Cooperative Research Report 346, International Council for the Exploration of the Sea.

Walther, B. D., Kingsford, M. J., O’Callaghan, M. D., and McCulloch, M. T. (2010). Interactive effects of ontogeny, food ration and temperature on elemental incorporation in otoliths of a coral reef fish. Environmental Biology of Fishes, 89(3-4):441-451, doi:10.1007/s10641010-9661-6.

Walther, B. D. and Limburg, K. E. (2012). The use of otolith chemistry to characterize diadromous migrations. Journal of Fish Biology, 81(2):796-825, doi:10.1111/j.10958649.2012.03371.x.

Zimmerman, C. E. (2005). Relationship of otolith strontium-to-calcium ratios and salinity: experimental validation for juvenile salmonids. Canadian Journal of Fisheries and Aquatic Sciences, 62(1):88-97, doi:10.1139/f04-182.

\section{Competing interests statement}

The authors declare there are no competing interests

\section{Contributors' statement}

CMA Conceptualization, Formal analysis, Methodology, Software, Validation, Visualization, Writing - original draft

KH Conceptualization, Funding acquisition, Writing - review \& editing, Supervision

SHS Data curation, Investigation, Writing - review \& editing

JHH Data curation, Investigation, Writing - review \& editing

TBT Data curation, Investigation, Writing - review \& editing

\section{Funding statement}

The study was supported by the Danish Ministry for Environment and Food and the European Union (grant No. 33113-B-16-034). 


\section{Data availability}

Code for the simulation study, illustrating the use of the model, is available in the supplementary material. Data from the case stdy is available from $\mathrm{KH}$ upon reasonable request. 